\title{
STATUS RESISTENSI NYAMUK AEDES $s p$ TERHADAP MALATHION DI KELURAHAN PAPAKELAN KABUPATEN MINAHASA
}

\author{
Lewi M. Kawatu ${ }^{1}$, Steven J. Soenjono ${ }^{2}$,Agnes T. Watung, ${ }^{3}$ \\ ${ }^{1)}$ Dinas Kesehatan Kabupaten Kepulauan Talaud \\ ${ }^{2,3)}$ Jurusan Kesehatan Lingkungan Poltekkes Kemenkes Manado \\ Email : lewikawatu@gmail.com
}

\begin{abstract}
The incidence of DHF in Minahasa District is still high, so that the DHF vector control efforts carried out by the Minahasa District Health Office are chemically using malathion. The type of this study was a study observational with a descriptive approach taken by sampling mosquitoes (larvae) of Aedes sp. in 100 houses carried out by method that is Simple random sampling simple random sampling of all individuals who are members of the population and have equal opportunities and are freely selected as members of the sample, consisting of one group, each test using 4 treatment tubes and 1 control tube. In each test tube, 25 female mosquitoes were inserted as many as 25 days in the first offspring. Data collection was obtained from the results of measurements using a resistance test (susceptibility test) with WHO standards in 1975 that is using four impregnated papers namely malathion $0.8 \%$. The results showed that the measurement of the first 1 hour had a yield of $8 \%-16 \%$ of the deaths ofMosquitoes Aedes sp.. with an average of $9 \%$ of deaths, while the 24-hour measurement results in $64 \%-76 \%$ of the deaths ofMosquitoes Aedes sp.. with an average of $70 \%$ of deaths, the use of malathion in the long term is the cause of the resistance of Aedes sp. Conclusion: the resistance status of Aedes sp. using insecticide malathion $(0.8 \%)$ in the Papakelan Village have shown resistance.
\end{abstract}

Keywords: Resistance, Aedes sp, Malathion

Abstrak. Kejadian DBD di Kabupaten Minahasa sampai sekarang masih tinggi, sehingga dalam upaya pengendalian vektor DBD yang dilakukan oleh Dinas Kesehatan Kabupaten Minahasa yaitu secara kimiawi dengan menggunakan malathion. Jenis penelitian ini adalah penelitian observasional dengan pendekatan deskriptif yang diambil pengambilan sampel nyamuk (larva) Aedes sp. pada 100 rumah yang dilakukan dengan metode Simple random sampling yaitu pengambilan acak sederhana seluruh individu yang menjadi anggota populasi dan memiliki peluang yang sama dan bebas dipilih sebagai anggota sampel, terdiri dari satu kelompok yakni setiap uji menggunakan 4 tabung perlakuan dan 1 tabung kontrol. Pada setiap tabung uji dimasukkan nyamuk betina umur $3-5$ hari sebanyak 25 ekor pada keturunan pertama. Pengumpulan data diperoleh dari hasil pengukuran menggunakan alat uji resistensi (susceptibility test) dengan standar WHO tahun 1975 yaitu menggunakan empat impregnated paper yaitu malation $0.8 \%$. Hasil penelitian menunjukkan bahwa dari pengukuran 1 jam pertama mempunyai hasil $8 \%-16 \%$ kematian Nyamuk Aedes sp. dengan rata-rata 9\% kematian, sedangkan pada pengukuran 24 jam mempunyai hasil 64\%-76\% kematian Nyamuk Aedes sp. dengan rata-rata $70 \%$ kematian, penggunaan malathion dalam jangka waktu yang lama menjadi penyebab terjadinya resistensi Aedes $s p$. Kesimpulan status resistensi nyamuk Aedes sp. menggunakan insektisida malation $(0,8 \%)$ di Kelurahan Papakelan telah menunjukkan resisten.

Kata kunci: Resistensi, Aedes sp, Malathion

Pengendalian Nyamuk dewasa dengan carafogging masih menjadi pilihan utama dalam penanggulangan Demam Berdarah Dengue (DBD). Upaya ini akan efektif jika nyamuk yang menjadi sasaran belum resisten terhadap insektisida yang dipakai. Contoh kasus resistensi pernah terjadi pada penggunaan pestisida Dichloro Diphenyl Trichloroethane (DDT), dimana pertama kali digunakan tahun 1946 dan kasus resistensi DDT terhadap Aedes sp. pertama kali dilaporkan tahun 1947 (Nuryanti, E. 2013).

Penggunaan malathion di Indonesia sebagai insektisida dalam program nasional pengendalian DBD sejak ada tahun 1970-an. Salah satu penentu efektivitas aplikasi kedua insektisida ini adalah tingkat resistensi nyamuk baik pada stadium larva maupun dewasa (Novita $\mathrm{K}$, 2016). Di beberapa wilayah di Indonesia, insektisida jenis ini masih digunakan dan dianggap efektif dalam pengendalian DBD. Namun dampak penggunaan insektisida berbahan dasar organofosfat ini apabila dilakukan secara terus menerus menyebabkan adanya bahaya resistensi nyamuk DBD (Prasetyowati, dkk. 2016).

Resistensi terhadap malathiontelah dilaporkan di beberapa lokasi. Resistensi nyamuk Aedes aegypti terhadap malathionjuga ditemukan dalam penelitian di Pakistan (Nazif, dkk. 2016). Resistensi terhadap malathion terjadi apabila nyamuk tidak dapat dibunuh oleh dosis standar atau berhasil menghindari kontak dengan 
insektisida melalui fenomena evolusi (WHO, 2012). Resistensi terhadap malathion di wilayah Indonesia juga dilaporkan antara lain di berbagai kota/kabupaten di Pulau Jawa (Sunaryo, dkk. 2014). Kalimantan (Safitri, 2013). Maluku (Tasane, 2015). Di Sumatera Selatan telah dilakukan uji kerentanan Ae. Aegypti terhadap insektisida malathion, dengan hasil strain dari 7 Kabupaten/Kota telah resisten, 3 Kabupaten/Kota berstatus toleran dan 1 Kabupaten masih rentan (Ambarita, dkk. 2015). Penelitian yang sama di empat kelurahan wilayah kerja KKP Bandar Udara Sam Ratulangi Manado menunjukkan Ae. aegyptiresisten terhadap malathion 0,8\% (Soenjono, 2011).

Malathion merupakan insektisida dari golongan organophosphat yang sudah dipakai untuk pemberantasan nyamuk di Kabupaten Minahasa sejak tahun 1980. Perbandingan campuran malathion yang dipakai untuk pengasapan secara nyata dilapangan menurut Program Pemberantasan DBD Dinas Kesehatan Kabupaten Minahasa menggunakan konsentrasi malathion 6\% dalam solar (1 liter malathion 96\% dilarutkan dalam 19 liter solar), hal ini sudah tidak memenuhi standar Kemenkes RI yaitu 1 liter insektisida malathion dicampur 19 liter solar (konsentrasi insektisida 5\%). Penggunaan konsentrasi $6 \%$ ini mulai diterapkan di lapangan sejak tahun 2001 karena pada tahun tersebut mulai ada keluhan masyarakat bahwa setelah dilakukan pengasapan nyamuk tidak mati sedangkan fogging telah dilaksanakan sesuai kriteria Kemenkes RI. (Dinas Kesehatan Kabupaten Minahasa, 2006).

Persebaran kasus DBD di Kabupaten Minahasa tahun 2017 mencapai 18 Puskesmas dari 22 Puskesmas, dengan jumlah kasus tertinggi berada di Puskesmas Papakelan Kecamatan Tondano Timur yaitu 98 kasus, untuk wilayah Kelurahan Papakelan berjumlah 35 kasus (Januari 2, Februari 4, Maret 5, April 5, Mei 7 dan Juni 12). (Dinkes Kabupaten Minahasa. 2017).

Wilayah Kelurahan Papakelan Kecamatan Tondano Timur secara geografis merupakan daerah pegunungan dengan kontur permukaan rata dan berbukit, pola pekerjaan masyarakat adalah petani, peternak babi dan ayam, pedagang, pegawai swasta dan pegawai negeri. Ciri khas pertanian di Kecamatan Tondano Timur berupa kelapa, cengkeh, padi, jagung dan tanaman holtikultura. Sumber mata air yang ada di Kelurahan Papakelan adalah PDAM dan Sumur gali. Lahan perkebunan kelapa, jagung, tanaman holtikultura, tempat minum ternak serta tempat penampungan air minum berpotensi sebagi tempat perkembangbiakan nyamuk (larva) Aedes sp.

Kelurahan Papakelan Kecamatan Tondano Timur Kabupaten Tondano umumnya habitat tempat perkembangbiakan (TP) Aedes sp. adalah tempayan, drum, bak, ember, tandon air, dispenser, fas bunga, talang air, kaleng, ban bekas, tempat minum ternak, lubang pohon atau pangkal bambu, sangat berpengaruh terhadap perkembangbiakan jentik nyamuk DBD atau Aedes sp. faktor lingkungan menunjang keberadaan sebagai tempat perkembangbiakan nyamuk (larva) tersebut. TP jentik nyamuk Aedes sp. dari bentuk telur, larva, pupa hingga menjadi dewasa sering tidak diperhatikan oleh masyarakat yang bertempat tinggal sangat dekat dengan lokasi TP tersebut. Selama ini pengendalian DBD menggunakan malathion $96 \%$ dengan konsentrasi $6 \%$, dalam 1 liter insektisida malathion di campur 19 liter solar.

Tujuan penelitian ini adalah untuk mengetahui status resistensi nyamuk Aedes sp. terhadap malathion $0,8 \%$ di Kelurahan Papakelan Kabupaten Minahasa.

\section{Metode}

Penelitian ini adalah penelitian observasional dengan pendekatan deskriptif untuk mengetahui seberapa besar resistensi nyamuk Aedes sp. terhadap malathion $0,8 \%$.

Populasi dalam penelitian ini adalah nyamuk (larva) Aedes sp. yang di survei dengan cara menciduk pada kontainer berisi air (tidak kontak dengan tanah), baik didalam maupun diluar rumah di Kelurahan Papakelan Kabupaten Minahasa. Pengambilan sampel nyamuk (larva) Aedes sp. dalam penelitian ini dilakukan dengan metode "Simple random sampling" yaitu pengambilan acak sederhana seluruh individu 
Kawatu, dkk. Status Resistensi Nyamuk Aedes sp,

yang menjadi anggota populasi dan memiliki peluang yang sama dan bebas dipilih sebagai anggota sampel (Sunyoto 2013). Jumlah sampel 100 rumah dibagi secara proporsional pada lima lingkungan dengan cara undi, maka didapat masing lingkungan 20 rumah. Jumlah rumah di Lingkungan $I=116$ rumah $(116: 20=5,8$ dibulatkan 6 rumah), Lingkungan II = 104 rumah (104: $20=5,2$ dibulatkan 5 rumah), Lingkungan $\mathrm{III}=109$ rumah $(109: 20=5,45$ dibulatkan 5 rumah), Lingkungan IV = 122 rumah $(122: 20=$ 6,1 dibulatkan 6 rumah), Lingkungan $\mathrm{V}=217$ rumah $(217: 20=10,85$ dibulatkan 11 rumah $)$.

\section{Kolonisasi nyamuk Aedes. $s p$}

Sampel nyamuk (larva) Aedes sp. diambil pada 100 rumah di Kelurahan Papakelan Kabupaten Minahasa pada kontainer yang ada di dalam dan di luar rumah penduduk, kemudian di bawa ke Laboratorium Poltekkes Kemenkes Manado Jurusan Kesehatan Lingkungan untuk dipelihara, diberi makanan berupa hati ayam, dalam beberapa hari larva akan menjadi pupa lalu dipindahkan ke dalam gelas kemudian dimasukkan dalam sangkar nyamuk, pupa akan berubah menjadi nyamuk dewasa dalam waktu 40-48 jam.

\section{Pengujian resistensi}

Pengujian resistensi dengan hewan uji nyamuk Aedes sp. dewasa, kondisi perut kenyang larutan gula, uji resistensi (susceptibility test) dengan standar WHO tahun 1975 yaitu menggunakan empat impregnated paper yaitu malation $0.8 \%$, setiap uji menggunakan 4 tabung perlakuan dan 1 tabung kontrol. Pada setiap tabung uji dimasukkan nyamuk betina umur 3-5 hari sebanyak 25 ekor. Nyamuk dibiarkan berkontak dengan kertas berinsektisida selama 1 jam, kemudian dipindahkan ke dalam tabung penyimpanan. Selama penyimpanan kelembaban dijaga dan pada tabung penyimpanan dilengkapi handuk basah dan larutan gula. Kematian nyamuk dihitung dan diamati 1 jam pertama dan setelah 24 jam penyimpanan. Nyamuk dinyatakan mati apabila nyamuk tersebut sudah tidak mampu bergerak lagi.

\section{Hasil}

Hasil uji resistensi secara suseptibilitas pada nyamuk Aedes sp. yang berasal dari Kelurahan Papakelan yang diukur dengan malathion menunjukan bahwa populasi nyamuk Aedes sp. yang berasal dari Kelurahan Papakelan telah resisten terhadap insektisida malathion $0,8 \%$ dengan persentase kematian nyamuk yang di uji sebesar $70 \%$.

Kematian nyamuk dewasa tertinggi pada 1 jam pertama didapat $16 \%$, sedangkan kematian nyamuk dewasa tertinggi pada 24 jam didapatkan $72 \%$. Seperti di lihat pada Tabel dibawah ini.

Tabel 1. Persentase Kematian Nyamuk Aedes sp. Pada Uji Susceptibility Insektisida Malathion 0,8\% Di Kelurahan Papakelan Kabupaten Minahasa Pengamatan 1 jam dan 24 jam.

\begin{tabular}{|c|c|c|c|c|c|c|c|c|c|}
\hline \multirow{3}{*}{ Ulangan } & \multicolumn{6}{|c|}{ Perlakuan } & \multicolumn{3}{|c|}{ Kontrol } \\
\hline & \multicolumn{3}{|c|}{ Pengamatan 1 jam } & \multicolumn{3}{|c|}{ Pengamatan 24 jam } & \multicolumn{3}{|c|}{ Pengamatan 1 jam dan 24 jam } \\
\hline & $\begin{array}{c}\text { Jlh } \\
\text { Nyamuk }\end{array}$ & $\begin{array}{c}\text { Jlh yg } \\
\text { mati }\end{array}$ & $\begin{array}{c}\% \\
\text { Kematian } \\
\end{array}$ & $\begin{array}{c}\text { Jlh } \\
\text { Nyamuk }\end{array}$ & $\begin{array}{c}\text { Jlh yg } \\
\text { mati }\end{array}$ & $\begin{array}{c}\% \\
\text { Kematian }\end{array}$ & $\begin{array}{c}\text { Jlh } \\
\text { Nyamuk }\end{array}$ & $\begin{array}{c}\text { Jlh yg } \\
\text { mati }\end{array}$ & $\begin{array}{c}\% \\
\text { Kematian } \\
\end{array}$ \\
\hline $\mathrm{I}$ & 25 & 3 & 12 & 25 & 18 & 72 & 25 & 0 & 0 \\
\hline II & 25 & 2 & 8 & 25 & 16 & 64 & 25 & 0 & 0 \\
\hline III & 25 & 2 & 8 & 25 & 17 & 68 & & & \\
\hline \multirow[t]{2}{*}{ IV } & 25 & 4 & 16 & 25 & 19 & 76 & & & \\
\hline & Rata-rata & 9 & 9 & Rata-rata & 70 & 70 & & & \\
\hline \multicolumn{2}{|c|}{ Suhu } & $29-32^{\circ} \mathrm{C}$ & & $29-32^{0} \mathrm{C}$ & & & & $29-32^{0} \mathrm{C}$ & \\
\hline \multicolumn{2}{|c|}{ Kelembaban } & $77-82 \%$ & & $77-82 \%$ & & & & $77-82 \%$ & \\
\hline
\end{tabular}


Tabel diatas menunjukkan bahwa persentase kematian nyamuk uji pada pengamatan 1 jam ditemukan (8-16\%) dan persentase kematian nyamuk uji pada pengamatan 24 jam ditemukan (64\%-76\%).

\section{Pembahasan}

Penelitian pada nyamuk Aedes sp. di Kelurahan Papakelan Kabupaten Minahasa menunjukkan bahwa total jumlah kematian adalah 70\%, nyamuk dari Kelurahan Papakelan Kabupaten Minahasa sudah resisten terhadap insektisida malathion $0,8 \%$ yang digunakan sebagai bahan penelitian merupakan insektisida golongan organofosfat yang memiliki toksisitas tinggi dibandingkan dengan golongan insektisida yang lain dan merupakan insektisida yang sering digunakan sebagai bahan fogging untuk penanggulangan KLB Demam Berdarah Dengue.

Pengujian suseptibilitas dilakukan untuk mengetahui status resistensi nyamuk Aedes sp yang berasal dari Kelurahan Papakelan, dengan melihat angka kematian nyamuk yang terpapar malathion, hasil membuktikan bahwa nyamuk yang berasal dari daerah tersebut telah mengalami resisten kematian $<80 \%$, hal itu dapat dilihat dari 25 ekor nyamuk yang terpapar oleh insektisida malathion $0,8 \%$ selama 1 jam mengalami kematian ataupun knockdown pada saat pengujian menunjukkan persentase kematian nyamuk uji antara $8-16 \%$. Knockdown effect malathion paling besar terjadi setelah dilakukan pengukuran baik terhadap nyamuk yang ada di dalam maupun di luar rumah pada pengamatan nyamuk yang pingsan/mati selama 60 menit (Muhammad dan Sofiana, 2016). Pada masa kontak 60 menit selama pengamatan 24 jam diperoleh kematian nyamuk sebesar $70 \%$ yang menunjukkan bahwa nyamuk Aedes sp. dilokasi tersebut sudah resisten terhadap malathion. Hal ini disebabkan oleh penggunaan malathion dengan cara fogging yang tidak sesuai aturan yang telah ditetapkan oleh Peraturan Menteri Kesehatan Republik Indonesia. Nyamuk Aedes sp. yang menjadi sampel uji yaitu nyamuk Aedes sp. betina yang kenyang gula, agar dalam pengujian ini nyamuk yang mati bukan karena kelaparan tetapi benar benar karena disebabkan oleh insektisida organofosfat (malathion). Pengujian suseptibilitas dilakukan dengan 4 kali ulangan perlakuan, yang dilakukan pada nyamuk Aedes $s p$. yang berasal dari Kelurahan Papakelan. Pada saat dilakukan perlakuan suhu dan kelembaban ruang juga diperhatikan agar nyamuk yang di uji tidak mati dikarenakan suhu yang terlalu rendah. Pada saat penelitian suhu ruangan $29-32^{\circ} \mathrm{C}$ dan kelembaban $77-82 \%$. Pengaturan suhu disesuaikan dengan penelitian yang dilakukan bahwa larva dipelihara pada suhu ruangan 29$32^{\circ} \mathrm{C}$ dan kelembaban $77-82 \%$ RH (Muhammad dan Sofiana, 2016).

Proses terjadinya penurunan resistensi serangga terhadap insektisida disebabkan oleh tiga faktor yaitu 1) Faktor genetik diketahui adanya sejumlah gen yang berperan dalam pengendali resisten ( $R$-gen), baik dominan atau resesif, homozygote maupunheterozygote yang terdapat pada nyamuk maupun serangga lainnya. Faktor genetik seperti gen-gen yang menjadi pembentukan enzim esterase, yang dapat menyebabkan resistensi serangga terhadap insektisida organofosfat. Faktor genetik lain adalah gen Knock Down Resistence (KDR). 2) Faktor biologis meliputi adanya pergantian generasi, perkawinan monogami atau poligami dan waktu berakhirnya perkembangan. Selain itu faktor perilaku serangga juga mempengaruhi terjadinya resistensi seperti migrasi, isolasi, monofagi atau polifagi, serta kemampuan serangga di luar kebiasaannya dalam melakukan perlindungan terhadap bahaya atau perubahan tingkah laku. 3) Faktor operasional meliputi bahan kimia yang digunakan (golongan insektisida, kesamaan target dan sifat insektisida yang digunakan, resistensi residu, dan formulasi insektisida yang digunakan) serta aplikasi insektisida tersebut di lapangan. (Muhammad dan Sofiana, 2016).

Malathion termasuk ke dalam kelompok insektisida yang memiliki cara kerja dalam mengganggu sistem saraf pada tubuh serangga target. Malathion bekerja dengan cara menghambat enzim asetilkolinesterase (AChE) sehingga enzim ini tidak dapat menghidrolisis asetilkolin (ACh). ACh merupakan suatu neurotransmitter yang menstimulasi pembukaan saluran $\mathrm{Na}+$ dan $\mathrm{K}+$, sedangkan AChE merupakan katalis dari reaksi hidrolisis asetilkolin menjadi kolininaktif dan asetat 
(Nurjanah, 2013). Gejala yang ditimbulkan pada serangga sama seperti pola umum keracunan pada saraf yaitu adanya keresahan, hiperexiability, gemetaran, kejang, lumpuh dan mati.

Ciri khas malathion adalah mempunyai kemampuan melumpuhkan serangga dengan cepat toksisitasnya terhadap mamalia relatif rendah dan terhadap vertebrata kurang stabil, korosif, berbau, dan memiliki rantai karbon yang pendek. Juga bekerja sebagai racun perut, sebagai racun kontak (contact poison) dan racun inhalasi. Insektisida organofosfat merupakan racun saraf yang bekerja deagaa cara menghambat kolinestrase (ChE) yang mengakibatkan serangga sasaran mengalami kelumpuhan dan akhirnya mati (Djojosumarto, 2008).

\section{Kesimpulan}

Status resistensi nyamuk Aedes sp. dengan metode standar WHO (impregnated paper) menggunakan insektisida malation $(0,8 \%)$ di Kelurahan Papakelan telah menunjukkan resisten dengan kematian $70 \%$.

\section{Saran}

Perlu adanya penggantian atau rotasi jenis insektisida malathion untuk pengendalian penyakit DBD di wilayah kerja Puksemas Papakelan. Upaya pengendalian populasi Aedes $s p$. dengan menggunakan insektisida perlu dikurangi frekuensinya diganti dengan lebih menggiatkan gerakan $3 \mathrm{M}+$.

\section{Daftar Pustaka}

Ambarita L.P, Taviv Y, Budiyanto A, Sitorus H, Pahlepi R.I, Febriyanto. 2015. Tingkat Kerentanan Aedes aegypti (Linn) Terhadap Malathion di Pro Sumsel 43(2) : 97-104.

Dinkes Kabupaten Minahasa. 2006. Laporan Kegiatan Program pemberantasan penyakit Menular Demam Berdarah Kabupaten Minahasa.

Dinkes Kabupaten Minahasa. 2017. Laporan Kegiatan Program pemberantasan penyakit Menular Demam Berdarah Kabupaten Minahasa.

Djojosumarto, P. 2008. Teknik Aplikasi Pestisida Pertanian. Penerbit Kanisius. Yogyakarta
Muhammad S Rahman dan Liena Sofiana. 2016. Perbedaan Status Kerentanan Myamuk Aedes Aegypti Terhadap Malathion Di Kabupaten Bantul Yogyakarta. Universitas Negeri Semarang. Jurnal KEMAS 11 (2) (2016).1-8.

Nazif UK, Shams UK, Ansar UK, Inayat UR, Salahuddin UK and Shahid UK. 2016. Susceptibility status of Dengue vector (Aedes aegypti) against different insecticides in district Mansehra, Khyber Pakhtunkhwa, Pakistan. Joof Entomology and Zoology Studies. E-ISSN: 2320-7078

Nurjanah S. 2013. Status Kerentanan Vektor Aedes aegypti terhadap Insektisida dan Kaitannya dengan Kejadian Kasus Demam Berdarah di Kota Bogor. [Tesis]. Institut Pertanian Bogor.

Novita K. 2016. Uji Resistensi Malathion dan Sipermethrin Terhadap Nyamuk Aedes aegypti Di Daerah Endemis Demam Berdarah Dengue Kota Medan. USU.

Nuryanti, E. 2013. Perilaku Pemberantasan Sarang Nyamuk di Masyarakat, Jurnal KEMAS (1): 15-23.

Prasetyowati H, Joni H, Wahono T. 2016. Status Resistensi Aedes aegypti (Linn.) terhadap Organofosfat di Tiga Kotamadya DKI Jakarta. Loka Litbang P2B2 Ciamis. BALABA Vol.12 No.1: 23-30

Safitri. 2013. Pemetaan, Karakteristik Habitat dan Status Resistensi Aedes aegypti di Kota Banjarmasin Selatan, Kalimantan Selatan. Vektora 3 (2):136-48.

Soenjono, S.T. 2011. Status Kerentanan Nyamuk Aedes sp. (Diptera:Culicidae) Terhadap Malation Dan Aktivitas Enzim Esterase Non Spesifik Di Wilayah Kerja Kantor Kesehatan Pelabuhan Bandar Udara Sam Ratulangi Manado, Jurnal Kesehatan Lingkungan, (1): 1-6

Sunyoto D. 2013. "Statistik untuk Paramedis". Alfabeta, Bandung.

Sunaryo, Ikawati B, Rahmawati, Widiastuti D. 2014. Status resistensi vektor Demam Berdarah Dengue Aedes aegypti terhadap malathion $0,8 \%$, permethrin $0,25 \%$ di Provinsi Jawa Tengah. Jurnal Ekologi Kesehatan.13(2 Juni):146-52. 
JKL Volume 9 No. 1 April 2019

Tasane I. 2015. Uji resistensi malathion 0,8\% terhadap nyamuk Aedes Aegypti di wilayah fogging Kantor Kesehatan Pelabuhan Kelas II Ambon. [Thesis]. Semarang: Universitas Diponegoro, Kesehatan Masyarakat. Jurnal Kesmas Volume 3, Nomor 3, April 2015 (ISSN: 2356-3346)
Kawatu, dkk. Status Resistensi Nyamuk Aedes sp,

WHO. 2012. Test procedures for insecticide resistance monitoring in malaria vector mosquitoes. Geneva, Switzerland. Press. http://www.who.int/malaria. 